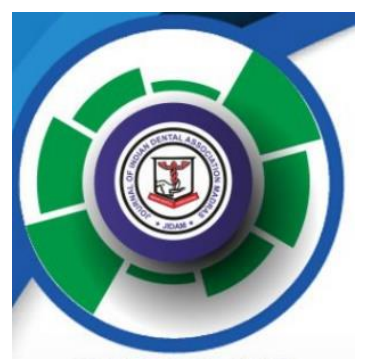

ORIGINAL ARTICLE

\title{
EFFECTIVENESS AND ORAL HEALTH STATUS AMONG INDIVIDUALS USING MODIFIED MANUAL TOOTH BRUSH - AN OBSERVATIONAL STUDY
}

\author{
Dr. Vijay Anand. M, Dr. Keerthi Narayan. V, Beno Gershon, Karthikeyan. K \\ Department of Prosthodontics and Crown \& Bridge, Thai Moogambigai Dental College and Hospital (Affiliated to Dr. MGR \\ Educational and Research Institute), Chennai, Tamilnadu, India- 600107.
}

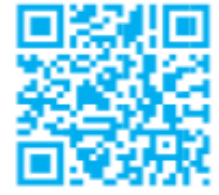

DOI: 10.37841/jidam_2021_V8_I4_01

Address for Correspondence:

Dr Keerthi Narayan V, MDS,

Senior lecturer,

Department of Oral Pathology and Microbiology,

Thai Moogambigai Dental College and Hospital,

Chennai, Tamilnadu, India- 600107.

Email id: keerthi.oralpath@drmgrdu.ac.in

Received: 23.11.2021

First Published: 12.12.2021

Accepted: 10.12.2021

Published: 27.12.2021

\begin{abstract}
Background of the study: Controlling plaque accumulation for prevention of gingivitis, periodontitis and dental caries effectively is determined by a number of personal and oral hygiene practice based factors. Tooth brush manufactures have put forth enormous effort in designing new models to improve performance characteristics.

Aim and objective: To evaluate the effectiveness and oral health status among individuals using modified design special tooth brush with beat sound developed to assist ideal brushing technique.
\end{abstract}

Material and methods: The present observational study included 20 study participants of age group between 21 to 45years. All the study participants were educated to use modified special tooth brush with beat sound regularly for a period of 21days and their oral hygiene status were evaluated by using Oral Hygiene Index Simplified (OHI-S) recorded at regular intervals on 1st, 7 th and 21st day.

Results: It was observed that all the study participants showed significant difference in the distribution of oral hygiene scores $(\mathrm{P}<.05)$ irrespective of gender and majority having a fair oral hygiene status with overall mean score of $2.22 \pm 0.3259$ slightly higher than previous mean score of $2.77 \pm 0.468$ ( $\mathrm{P}=.00026)$ and initial visit poor oral hygiene status mean score of $3.755 \pm$ $0.4796(\mathrm{P}=.04579)$.

Conclusion: Within the limitation of this study, not taking consideration of confounding factors it can be concluded that modified special tooth brush with beat sound technique show significant difference in the Oral Hygiene Index score of an individual during the observation period thus improving the overall oral health status.

Keywords: Calculus index, Manual brushing, Oral Hygiene, Soft debris, specially designed tooth brush. 


\section{INTRODUCTION}

Oral health status is considered as an important diagnostic element to determine the overall health status that depends on physiological, biological, environmental, psychological, and social well-being of an individual ${ }^{1}$. Oral health is often compromised due to poor oral hygiene practices, nutritional and dietary approaches, systemic diseases, hormonal changes, stress and addictive habits like tobacco, pan chewing and consumption of alcohol ${ }^{2}$. It has been well established that accumulation of debris, dental plaque and calculus plays a vital role in initiation and development of dental caries, gingival and periodontal diseases. Consequently effective removal of supra-gingival plaque and calculus by oral hygiene practices such as appropriate brushing technique, use of adjunctive oral hygiene aids, mouthwashes, interdental toothbrushes, toothpicks and floss had shown a profound effect on the gingival and oral health ${ }^{3}$.

Controlling plaque accumulation for prevention of gingivitis, periodontitis and dental caries effectively is determined by a number of personal and oral hygiene practice based factors. Often brushing technique is recognized as the important aspect along with others like design of the toothbrush, tooth-brushing frequency and duration of use ${ }^{4}$. Inappropriate tooth brushing techniques, improper use of oral hygiene aids involving excessive pressure may not efficiently or effectively remove plaque but also considerably increase gingival recession and loss of tooth substance by mechanical abrasion ${ }^{5}$. Recent literature studies have shown dental professionals perform various oral health promotion activities both at the individual and community level to incorporate significant knowledge and awareness towards importance of oral hygiene practices among the general population ${ }^{6}$.

On the other hand design or morphometrics of the toothbrush is highly influenced by technological, physical and mechanical properties of the toothbrush bristles and the shape, size, arrangement of the tooth brush head in relation to handle ${ }^{7}$. Hence, the manufacturers of toothbrushes currently aim to integrate innovations in the brush head design that will help to compensate for non-ideal toothbrushing technique and related factors ${ }^{8}$. Thus, the combined focus on both personal and oral hygiene based factors is critical to control oral diseases, promotion of oral health and improve the quality of life. In the present study, effectiveness of a specially modified manual tooth brush developed to assist ideal brushing technique in order to remove plaque and debris to enhance good oral health was evaluated.

\section{METHODOLOGY:}

A total of 20 participants (10 males and 10 females) age group between 21 to 45years were randomly selected into this observational study having a cross-sectional design. All the study participants were given modified tooth brush (V-Beat TM Manufactured and Marketed by VISBRODENT Innovations) which is specially designed to guide proper brushing technique by presence of beads in the shank portion capable of producing beat sound (Fig 1). The beads are arranged at a regular interval for effective movement along the direction of vertical and circular motions with the handle producing noise only at the time of ideal brushing technique performed. The instructions were given and study participants were educated to use this modified special tooth brush regularly twice a day for a period of 21days and not to use any other oral hygiene aids during the evaluation period.

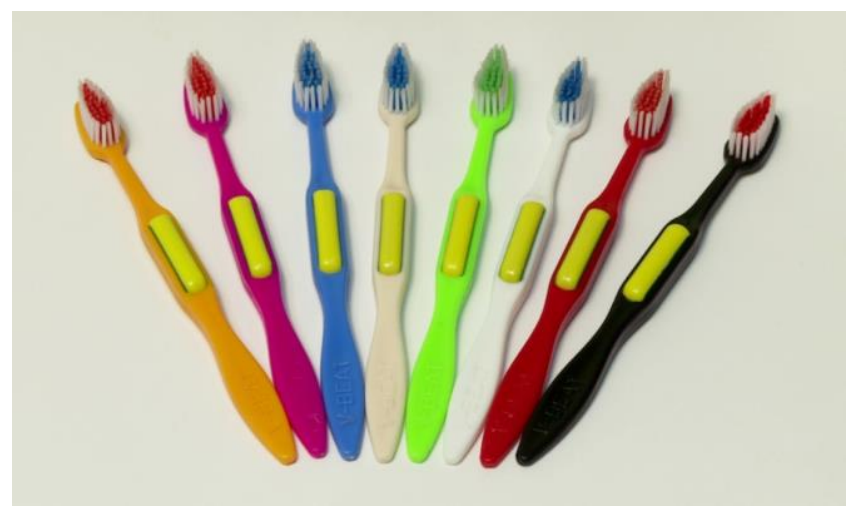

Fig 1: Photograph showing the modified tooth brush with presence of beads in the shank portion capable of producing beat sound (V-Beat TM Manufactured and Marketed by VISBRODENT INNOVATIONS)

Oral hygiene status was evaluated by using Oral hygiene index simplified (OHI-S) index given by John C Greene and Jack R Vermillion (1964) recorded at the time of initial visit (pre-assessment) followed by 1st, 7th and 21 st day at regular intervals. Indices scores were calculated based on the Scoring Criteria. OHI-S has two components namely Simplified Debris Index (DI-S) and Simplified Calculus index (CI-S) recorded on six teeth that includes 3 upper/Maxillary tooth- right first molar (16- Buccal), left first molar (26- Buccal) and Right central incisors (11Labial); and 3 lower/Mandibular tooth- left first molar (36Lingual), Right first molar (46- Lingual) and left central incisors (31-Labial). 


\section{EXAMINATION AND SCORING:}

For Debris Index, the surface area covered by debris is estimated by running the side of a shepherd's hook along the tooth surface being examined. DI- S- Scores: 0- No debris or stain present; 1 - soft debris covering not more than $1 / 3$ rd of the tooth surface or presence of extrinsic stains without other debris; 2- soft debris covering more than $1 / 3$ rd but not more than $2 / 3$ rd of the exposed tooth surface; 3 - soft debris covering more than $2 / 3 \mathrm{rd}$ of the exposed tooth surface.

For calculus index, supra-gingival calculus usually white to yellowish brown in color occlusal to the free gingival margin is examined. CI-S- Scores: 0- No calculus present; 1- Supra-gingival calculus covering not more than $1 / 3 \mathrm{rd}$ of the exposed tooth surface; 2- Supra-gingival calculus covering more than $1 / 3$ rd but not more than $2 / 3$ rd of the exposed tooth surface or presence of flecks; 3- Supragingival calculus covering more than $2 / 3$ rd of the exposed tooth surface or presence of heavy calculus band.

\section{CALCULATION AND INTERPRETATION:}

For each individual the final OHI-S is calculated by adding DI-S and CI-S scores based on the number of surfaces examined. Overall score of 0.0-1.2- Good; 1.3-3.0- Fair; 3.1 to 6.0- Poor was graded. All the data collected was tabulated. Statistical analysis was performed by using SPSS software version22.0 (SPSS V22.0 Illinois, Chicago).

\section{RESULTS:}

On analysis of the given data the mean age of the study population was observed to be $38.9 \pm 5.8839$ years (mean \pm S.D) with 2.753 at $95 \%$ confidence level comprising of 10 (50\%) male and 10 (50\%) female participants. There was a significant difference in the distribution of oral hygiene scores $(\mathrm{P}<.05)$ with majority of the participants having a poor oral hygiene status with mean score of $3.755 \pm 0.4796$ during pre-assessment before the initiation of the study among which females (3.89) had slightly higher scores than male group (3.62). No significant gender differences were observed on the 1st day among female (3.47) and male (3.29) participants in the OHI-S scores with overall mean score of $3.38 \pm 0.4884$ significant at $\mathrm{p}<.05$ (Table 1 ).

Table 1: Table Showing the Individual Pre- Assessment and Day 1 Mean OHI-S Score among the study population with OneWay ANOVA analysis

\begin{tabular}{|c|c|c|c|c|c|c|c|}
\hline S NO & $\begin{array}{c}\text { Age } \\
\text { (In years) }\end{array}$ & Gender & $\begin{array}{c}\text { Individual } \\
\text { Pre- } \\
\text { Assessment } \\
\text { OHI-S Score }\end{array}$ & $\begin{array}{l}\text { Pre- Assessment } \\
\text { OHI-S Score } \\
(\text { mean } \pm \text { S.D) }\end{array}$ & $\begin{array}{l}\text { Individual } \\
\text { OHI-S Score } \\
\text { on Day } 1\end{array}$ & $\begin{array}{l}\text { Mean OHI-S } \\
\text { Score on Day } 1 \\
(\text { mean } \pm \text { S.D })\end{array}$ & p-value \\
\hline 1. & 46 & Male & 3.1 & \multirow[t]{10}{*}{$3.62 \pm 0.4756$} & 2.8 & \multirow[t]{10}{*}{$3.29 \pm 0.3843$} & \multirow[t]{10}{*}{.32347} \\
\hline 2. & 27 & Male & 3.1 & & 2.9 & & \\
\hline 3. & 30 & Male & 4.3 & & 3.6 & & \\
\hline 4. & 36 & Male & 3.5 & & 3.2 & & \\
\hline 5. & 39 & Male & 4.1 & & 3.9 & & \\
\hline 6. & 35 & Male & 3.3 & & 3.1 & & \\
\hline 7. & 38 & Male & 3.5 & & 3.2 & & \\
\hline 8. & 46 & Male & 4.4 & & 3.9 & & \\
\hline 9. & 38 & Male & 3.4 & & 3.1 & & \\
\hline 10. & 39 & Male & 3.5 & & 3.2 & & \\
\hline 11. & 50 & Female & 3.6 & \multirow[t]{10}{*}{$3.89 \pm 0.4677$} & 2.7 & \multirow[t]{10}{*}{$3.47 \pm 0.5813$} & \multirow[t]{10}{*}{.17974} \\
\hline 12. & 35 & Female & 3.6 & & 3.4 & & \\
\hline 13. & 32 & Female & 3.7 & & 2.9 & & \\
\hline 14. & 38 & Female & 4.8 & & 4.5 & & \\
\hline 15. & 45 & Female & 3.2 & & 2.8 & & \\
\hline 16. & 44 & Female & 4.5 & & 4.2 & & \\
\hline 17. & 34 & Female & 3.8 & & 3.5 & & \\
\hline 18. & 44 & Female & 4.1 & & 3.7 & & \\
\hline 19. & 42 & Female & 3.9 & & 3.6 & & \\
\hline 20. & 40 & Female & 3.7 & & 3.4 & & \\
\hline
\end{tabular}


Keerthi et al: Effectiveness and Oral Health Status among Individuals Using Modified Manual Tooth Brush

\begin{tabular}{|c|c|c|c|c|c|c|c|}
\hline & $38.9 \pm 5.883$ & $\begin{array}{c}\text { (mean } \pm \\
\text { S.D) }\end{array}$ & Overall & $3.755 \pm 0.4796$ & Overall & $3.38 \pm 0.4884$ & $\mathbf{. 0 4 5 7 9 *}$ \\
\hline
\end{tabular}

$* \mathrm{p}<.05-$ Significant

Table 2: Table Showing the Individual Day 7 and Day 21 Mean OHI-S Score among the study population with One-Way ANOVA analysis

\begin{tabular}{|c|c|c|c|c|c|c|c|}
\hline $\mathrm{S} \mathrm{NO}$ & $\begin{array}{c}\text { Age } \\
\text { (In years) }\end{array}$ & Gender & $\begin{array}{c}\text { Individual } \\
\text { OHI-S Score } \\
\text { on Day } 7\end{array}$ & $\begin{array}{c}\text { Mean OHI-S } \\
\text { Score on Day } 7 \\
(\text { mean } \pm \text { S.D })\end{array}$ & $\begin{array}{c}\text { Individual } \\
\text { OHI-S Score } \\
\text { on Day } 21\end{array}$ & $\begin{array}{c}\text { Mean OHI-S } \\
\text { Score on Day } \\
21 \text { (mean } \pm \\
\text { S.D) } \\
\end{array}$ & p-value \\
\hline 1. & 46 & Male & 1.6 & \multirow{10}{*}{$\begin{array}{c}2.64 \pm 0.4671 \\
(\mathbf{p}=. \mathbf{0 0 0 6})^{*}\end{array}$} & 1.4 & \multirow{10}{*}{$\begin{array}{c}2.1 \pm 0.3682 \\
(\mathbf{p}=. \mathbf{0 0 0 0}) *\end{array}$} & \multirow[t]{10}{*}{$.0000 *$} \\
\hline 2. & 27 & Male & 2.4 & & 2.1 & & \\
\hline 3. & 30 & Male & 3.4 & & 2.8 & & \\
\hline 4. & 36 & Male & 2.8 & & 2.1 & & \\
\hline 5. & 39 & Male & 2.8 & & 2.4 & & \\
\hline 6. & 35 & Male & 2.5 & & 1.9 & & \\
\hline 7. & 38 & Male & 2.9 & & 2.1 & & \\
\hline 8. & 46 & Male & 2.8 & & 2.2 & & \\
\hline 9. & 38 & Male & 2.4 & & 1.8 & & \\
\hline 10. & 39 & Male & 2.8 & & 2.2 & & \\
\hline 11. & 50 & Female & 2.4 & \multirow{10}{*}{$\begin{array}{l}2.9 \pm 0.4546 \\
(\mathbf{p}=.00012) *\end{array}$} & 2.1 & \multirow{10}{*}{$\begin{array}{c}2.35 \pm 0.2321 \\
(\mathbf{p}=. \mathbf{0 0 0 0}) *\end{array}$} & \multirow[t]{10}{*}{$.0000 *$} \\
\hline 12. & 35 & Female & 2.4 & & 2.3 & & \\
\hline 13. & 32 & Female & 2.7 & & 2.3 & & \\
\hline 14. & 38 & Female & 3.6 & & 2.7 & & \\
\hline 15. & 45 & Female & 2.4 & & 1.9 & & \\
\hline 16. & 44 & Female & 3.6 & & 2.6 & & \\
\hline 17. & 34 & Female & 2.8 & & 2.3 & & \\
\hline 18. & 44 & Female & 3.1 & & 2.4 & & \\
\hline 19. & 42 & Female & 3.1 & & 2.5 & & \\
\hline \multirow[t]{2}{*}{20.} & 40 & Female & 2.9 & & 2.4 & & \\
\hline & $\begin{array}{c}38.9 \pm \\
5.883 \\
\end{array}$ & $\begin{array}{c}\text { (mean } \pm \\
\text { S.D) }\end{array}$ & Overall Score & $\begin{array}{l}2.77 \pm 0.468 \\
(\mathbf{P}=. \mathbf{0 0 0 2 6}) *\end{array}$ & $\begin{array}{c}\text { Overall score } \\
\text { p value }\end{array}$ & $2.22 \pm 0.3259$ & $.0000 *$ \\
\hline
\end{tabular}

$* \mathrm{p}<.05$ - Significant

Table 3: Table showing One-way ANOVA test for independent measures and Post Hoc Tukey HSD test

\begin{tabular}{|c|c|c|c|}
\hline Pairwise Comparisons & Mean & $\begin{array}{l}\text { HSD Difference in } \\
\text { Mean }\end{array}$ & $\mathrm{p}$ value \\
\hline Post Hoc Tukey HSD (beta) & & $\begin{array}{l}\text { HSD. } 05=0.3700 \\
\text { HSD. } 01=0.4535\end{array}$ & Q.05 = 3.7149 Q.01 = 4.5530 \\
\hline \multirow[t]{2}{*}{ T1:T2 } & $\mathrm{M} 1=3.75$ & 0.38 & $Q=3.76(p=.04579)^{*}$ \\
\hline & $\mathrm{M} 2=3.38$ & & \\
\hline \multirow[t]{2}{*}{ T1:T3 } & $\mathrm{M} 1=3.75$ & 0.98 & $Q=9.89(p=.00000)^{*}$ \\
\hline & M3 $=2.77$ & & \\
\hline \multirow[t]{2}{*}{ T1:T4 } & $\mathrm{M} 1=3.75$ & 1.53 & $Q=15.36(p=.00000)^{*}$ \\
\hline & $\mathrm{M} 4=2.23$ & & \\
\hline T2:T3 & $\mathrm{M} 2=3.38$ & 0.61 & $Q=6.12(p=.00026)^{*}$ \\
\hline
\end{tabular}


Keerthi et al: Effectiveness and Oral Health Status among Individuals Using Modified Manual Tooth Brush

\begin{tabular}{|c|c|c|c|}
\hline & M3 $=2.77$ & & \\
\hline T2:T4 & M2 $=3.38$ & 1.15 & $\mathbf{Q = 1 1 . 6 0 ~ ( p = . 0 0 0 0 0})^{*}$ \\
\hline & M4 $=2.23$ & & \\
\hline T3:T4 & M3 $=2.77$ & 0.54 & $\mathbf{Q = 5 . 4 7 ~ ( p = . 0 0 1 2 9})^{*}$ \\
\hline & M4 $=2.23$ & & \\
\hline
\end{tabular}

*p<.05- Significant T1 -Pre assessment OHI-S score, T2- Day 1 OHI-S Score, T3- Day 7 OHI-S Score, T4- Day21 OHI-S Score

Evaluation of the OHI-S score on Day 7 showed significant difference in the distribution of oral hygiene scores $(\mathrm{P}<$ .05) majority having a fair oral hygiene status with overall mean score of $2.77 \pm 0.468$ among which females (2.9) had greater scores than male group $(2.64)(\mathrm{P}<.05)$ compared to the previous visit. Final analysis on Day 21 also showed significant difference in the distribution of oral hygiene scores $(\mathrm{P}<.05)$ majority having a fair oral hygiene status with overall mean score of $2.22 \pm 0.3259$ slightly higher than previous and initial visits (Table 2). One-way ANOVA test for independent measures and Post Hoc Tukey HSD test for pairwise comparison showed a significant difference in the oral hygiene status of an individual during the observation period $(\mathrm{P}<.05)($ Table 3$)$.

\section{DISCUSSION:}

In the early 19th century bristled tooth brushes were introduced for manual brushing that enhances oral health of an individual by reducing plaque and calculus deposition, prevent bad breath, reduce inflammation of gingival and periodontal tissues, provide sense of freshness and also psychologically impact the esthetic appearance during smile or speech $^{9}$. The bristles were initially made of nylon supported by plastic handle to ensure affordability, and availability to every individual making brushing a common practice in day to day life. Since then numerous modification and inventiveness in design, shape, size and type of materials has been applied and marketed ${ }^{10}$. However there is inadequate evidence that one specific toothbrush design is superior and alternative to other.

Currently tooth brushes are manufactured to remove accumulation of food debris and plaque in the interproximal areas apart from routine cleaning surfaces. Vibhute and Vandana in a meta-analysis observed mechanical plaque removal with a manual modified or specific toothbrush remains the principal routine practice of maintaining good oral hygiene for the majority of the population ${ }^{11}$. Van der Weijden GA et $\mathrm{al}^{12}$, Slot DE et $\mathrm{al}^{13}$ observed 1-min tooth brushing exercise in individuals following their customary method irrespective of tooth brushes used significantly reduced the plaque score by $39 \%$ whereas in the present study comparison showed a significant difference in the oral hygiene index score $(40 \%-50 \%)$ of an individual during the observation period indicating the influence of effective brushing technique and tooth brush desired.

Slot DE et $\mathrm{al}^{13}$ in a systemic review demonstrated an average variation of $30-53 \%$ on the plaque index depending on bristle tuft configuration and angulation of the bristle design. The authors concluded that brushing duration, technique with appropriate guidance contribute to the efficacy. Recent studies have shown powered tooth brushes represent an effective alternative for Manual tooth brushes in removing debris and plaque however long term effectiveness assessment studies have showed limited role in slowing down the initiation or progression of periodontal diseases $^{14,15,16}$.

Taschner et $\mathrm{al}^{17}$, Rosema et $\mathrm{al}^{18}$ in their respective studies evaluated the efficacy of manual, electric tooth brushes and modified tooth brushes in removal of plaque and debris and showed manual tooth brushes with modifications incorporated accompanied by proper brushing technique improved the effectiveness of oral hygiene practices. Although statistics from brushing exercise studies can be viewed under limited information, a toothbrush that removes more plaque as assessed under controlled environment condition following a single-use brushing might differ in long term different home-based conditions yet this technique is expected to provide improved plaque control over time and, as a result, have long-term benefits on overall gingival and periodontal health ${ }^{19,20}$.

Tooth brush manufactures have put forth enormous effort in designing new models to improve performance characteristics. Slot DE et al ${ }^{13}$ exhibited that ideal brushing technique guidance significantly influence multilevel bristles to reach farther distance between the teeth and cover large surfaces. In this study we have modified tooth brush (V-Beat TM Manufactured and Marketed by 
VISBRODENT Innovations) which is specially designed to guide proper brushing technique by presence of beads in the shank portion capable of producing beat sound. The beads are arranged at a regular interval for effective movement along the direction of vertical and circular motions with the handle producing noise only at the time of ideal brushing technique performed ${ }^{21}$. Higgins ${ }^{22}$ specified that performing multiple studies by different groups in different places with diverse methods, would be a real estimation of the particular or specific parameter evaluated. Variations in several studies reflects the nature of routine oral hygiene techniques followed along with methodology observed and parameters taken into consideration.

\section{CONCLUSION:}

Within the limitation of this study, not taking consideration of confounding factors, based on clinical observations it can be concluded that modified special tooth brush with beat sound technique show significant difference in the oral hygiene index score of an individual during the observation period thus improving the overall oral health status. Further studies to confirm these findings in different environment and larger population groups combined with long term follow up of individuals is needed to demonstrate the effectiveness of modified special tooth brush method.

\section{FINANCIAL SUPPORT AND SPONSORSHIP}

Nil

\section{CONFLICTS OF INTEREST}

There are no conflicts of interest.

\section{REFERNCES:}

1. Hayasaki H, Saitoh I, Nakakura-Ohshima K, Hanasaki M, Nogami Y, Nakajima T, Inada E, Iwasaki T, Iwase $\mathrm{Y}$, Sawami T, Kawasaki K. Tooth brushing for oral prophylaxis. Japanese Dental Science Review. 2014 Aug 1; 50(3):69-77.

2. Shah N, Sundaram KR. Impact of socio-demographic variables, oral hygiene practices, oral habits and diet on dental caries experience of Indian elderly: A community-based study. Gerodontology 2004; 21:43-50.

3. Petker W, Weik U, Margraf-Stiksrud J, Deinzer R. Oral cleanliness in daily users of powered vs. manual toothbrushes-a cross-sectional study. BMC oral health. 2019 Dec; 19(1):1-9.
4. Jeong MJ, Cho HA, Kim SY, Kang KR, Lee EB, Lee YJ, Choi JH, Kil KS, Lee MH, Jeong SJ, Lim DS. Effect of Ultra-Soft and Soft Toothbrushes on the Removal of Plaque and Tooth Abrasion. Journal of dental hygiene science. 2018; 18(3):164-71.

5. Bizhang M, Schmidt I, Chun YH, Arnold WH, Zimmer S. Toothbrush abrasivity in a long-term simulation on human dentin depends on brushing mode and bristle arrangement. PloS one. $2017 \mathrm{Feb}$ 21; 12(2):e0172060.

6. Oberoi SS, Mohanty V, Mahajan A, Oberoi A. Evaluating awareness regarding oral hygiene practices and exploring gender differences among patients attending for oral prophylaxis. Journal of Indian Society of Periodontology. 2014 May; 18(3):369.

7. Cifcibasi E, Koyuncuoglu CZ, Baser U, Bozacioglu B, Kasali K, Cintan S. Comparison of manual toothbrushes with different bristle designs in terms of cleaning efficacy and potential role on gingival recession. European journal of dentistry. 2014 Jul; 8(03):395-401.

8. Warad LP, Patil CL, Dabholkar AP, Rajan DT, Monali G. Comparative evaluation of two manual toothbrushes with different bristle designs for plaque removal efficacy in females-A clinical study. Journal of Interdisciplinary Dentistry. 2019 Sep 1; 9(3):114.

9. Jepsen $\mathrm{S}$. The role of manual toothbrushes in effective plaque control: advantages and limitations. In: Lang NP, Attstro"m R, Lo"e H, eds. Proceedings of the European Workshop on Mechanical Plaque Control. London: Quintessence, 1998, pp. 121-137.

10. Loe H. Half a Century of Plaque Removal. What's Next? Millennium Lecture EuroPerio 2000. London: The Parthenon Publishing Group; 2000.

11. Vibhute A, Vandana KL. The effectiveness of manual versus powered toothbrushes for plaque removal and gingival health: A meta-analysis. Journal of Indian society of periodontology. 2012 Apr; 16(2):156.

12. Van der Weijden GA, Hioe KP. A systematic review of the effectiveness of self-performed mechanical plaque removal in adults with gingivitis using a manual toothbrush. J Clin Periodontol 2005; 32 (Suppl 6): 214-228. 
Keerthi et al: Effectiveness and Oral Health Status among Individuals Using Modified Manual Tooth Brush

13. Slot DE, Wiggelinkhuizen L, Rosema NA, Van der Weijden GA. The efficacy of manual toothbrushes following a brushing exercise: a systematic review. International journal of dental hygiene. 2012 Aug; 10(3):187-97.

14. Deery C, Heanue M, Deacon S, Robinson PG, Walmsley AD, Worthington H, Shaw W, Glenny AM. The effectiveness of manual versus powered toothbrushes for dental health: a systematic review. Journal of dentistry. 2004 Mar 1; 32(3):197-211.

15. Pitchika V, Pink C, Völzke H, Welk A, Kocher T, Holtfreter B. Long-term impact of powered toothbrush on oral health: 11-year cohort study. Journal of clinical periodontology. 2019 Jul; 46(7):713-22.

16. Schmidt JC, Zaugg C, Weiger R, Walter C. Brushing without brushing? - a review of the efficacy of powered toothbrushes in noncontact biofilm removal. Clinical oral investigations. 2013 Apr; 17(3):687-709.

17. Taschner M, Rumi K, Master AS, Wei J, Strate J, Pelka M. Comparing efficacy of plaque removal using professionally applied manual and power toothbrushes in 4-to 7-year-old children. Pediatric dentistry. 2012 Feb 15; 34(1):61-5.

18. Rosema NA, Hennequin-Hoenderdos NL, Versteeg PA, van Palenstein Helderman WH, Van der Velden U, Van der Weijden GA. Plaque-removing efficacy of new and used manual toothbrushes-a professional brushing study. International journal of dental hygiene. 2013 Nov; 11(4):237-43.

19. Schaeken MJM, Sturm D, Master A, Jenkins W, Schmitt P. A randomized, single-use study to compare plaque removal ability of sonicare flexcare and oral-B Triumph professional care 9000. Compend Contin Educ Dent 2007; 28 (Suppl 1): 29-34.

20. Singh SM, Battista GW, Rustogi KN et al. The comparative plaque removal efficacy of two advanced manual toothbrush designs in two independent clinical studies. J Clin Dent 2001; 12: 83-86.

21. Vijay Anand M, Keerthi Narayan V, Priya M, Keerthana D. Oral health problems related to preand post-medications among diabetic individuals:
A cross sectional study. International Journal of Applied Dental Sciences 2020; 6(1): 24-27.

22. Higgins JP. Commentary: Heterogeneity in metaanalysis should be expected and appropriately quantified. Int J Epidemiol 2008; 37: 1158-1160. 